\title{
Index rerum, vol. 9
}

Aorta 15 Artigacts 15 Av shunt 69

Biliary cirrhosis 40

Capillaries 11 Capillary permeability 62 Contrast of the liver 40 Coronary pain 89 Coumarin 92, 99

Dextran oedema 99

Domestic and wild mammals 34

Duodenal villi 11

Endothelium 11, 15, 106 Enzymes 53

Fast and slow muscle 1 Fine structure 106 Forearm 89

Impedance, arterial 81 Initial lymphatic 106 Intercellular bridges 15 Intercellular contacts 11 Intercellular junction 106

Limb blood flow 69 Lymph drainage 99 Lymphatics of the liver 40 Lymphedema 92

Lymphostasis - cholostasis 40

Massage 92 Mesenteric arteries 27

Neonatal circulation 1 Noradrenaline 27 Norepinephrine 1

Oedema 62

Ontogenic development 1

Peripheral heart 81 Powder 40 Pulse volume 89

Red and white muscle 1

Regulation of the limb circulation 69

Regulation of the systemic circulation 69

Scanning electron microscopy 15

Shunt flow 69

Silver staining 15

Tantal 40

Terminal vascular bed 1

Uterine artery 34

Varices 53 Vasa vasorum 34 Vascular smooth muscle 27 Vascular reactivity 1 Vasoconstrictor escape 27 Veins 53

Venous insufficiency 62 Venoruton 62

Wave amplification 81 